

\title{
A TURBULENCE MODEL FOR ICED AIRFOILS AND ITS VALIDATION
}

\author{
Jaiwon Shin $^{+}$ \\ National Aeronautics and Space Administration \\ Lewis Research Center \\ Cleveland, Ohio 44135
}

and

\author{
Hsun H. Chen* and Tuncer Cebeci** \\ California State University \\ Long Beach, California 90801
}

\begin{abstract}
A turbulence model based on the extension of the algebraic eddy-viscosity formulation of Cebeci and Smith developed for twodimensional flows over smooth and rough surfaces is described for iced airfoils and validated for computed ice shapes obtained for a range of total temperatures varying from $28^{\circ} \mathrm{F}$ to $-15^{\circ} \mathrm{F}$. The validation is made with an interactive boundary-layer method which employs a panel method to compute the inviscid flow and an inverse finite-difference boundary-layer method to compute the viscous flow. The interaction between inviscid and viscous flows is established by the use of the Hilbert integral.

The calculated drag coefficients compare well with recent experimental data taken at the NASA Lewis Icing Research Tunnel (IRT) and show that, in general, the drag increase due to ice accretion can be predicted well and efficiently.
\end{abstract}

\subsection{Introduction}

The importance of surface roughness has been recognized for many years, with early experiments performed in relation to boundarylayer flows by Schlichting ${ }^{1}$ and Nikuradse ${ }^{2}$. In these early papers, it was already evident that roughness might be considered with or without knowledge of the detailed geometry of the roughness elements and that, in both cases, experiments were necessary to indicate the influences on pressure drop, skin-friction and heat transfer. When the elements are well defined, regular and with a characteristic dimension that approaches the thickness of the boundary layer, as with the ribs used to promote turbulence and augment heat transfer in some nuclear reactors, it is possible to solve the Navier-Stokes equations from the wall to a region outside the shear layer and thereby provide detailed spatially-local values of velocity and temperature and their gradients. This approach is likely to require the use of cyclic boundary conditions, and uncertainties due to numerical and turbulence assumptions are inevitable. Where they do not meet the above requirements, it was not possible to accurately model the details of the geometry of the roughness elements and of the flow characteristics in their immediate vicinity.

The approach to the representation of discrete roughness elements considered by Coleman and used in subsequent papers, for example that of Hosni, Coleman and Taylor ${ }^{3}$ is, in some respects, a hybrid between the extremes implied above. Thus, discrete roughness was considered in terms of a local element Reynolds number where the dimension attempted to represent the geometry. Wall-shear stress was then defined in two parts, one due to the usual form of skin friction with a blockage

- +Aerospace Engineer, Member AIAA.

*Associate Professor, Senior Member AIAA. **Professor and Chairman; Fellow AIAA. 
parameter and the latter based on the roughness Reynolds number. A similar approach was taken to deal with the heat transfer coefficient and Stanton number. These definitions, and an appropriate numerical description of the roughness parameters, were used within a computer code to solve numerically twodimensional boundary-layer equations with very creditable results. Two hundred and fifty grid nodes were required to define the boundary layer at each streamwise location with up to 60 below the crest of the elements. This last feature persuaded Boyle and Civinskas ${ }^{4}$ that this approach was inappropriate for use within their calculation method, which was based on the solution of thin-layer, Navier-Stokes equations, and it is self-evident that it would be less appropriate for use with higher-order forms of the Navier-Stokes equations.

The alternative approach is to make use of an equivalent sand-grain roughness, as by Nikuradse ${ }^{2}$, where this quantity has been determined from experiment, and this was preferred by Boyle and Civinskas who chose to make use of the formulation of Cebeci and Smith $^{5}$ as modified by Cebeci and Chang6. This has the advantage that the turbulent flow calculations with surface roughness can be performed in the same manner as for smooth surfaces without the need of the 60 near-wall grid nodes of Hosni et al. Just as this economy is necessary for Navier-Stokes solvers, it is required with interactive boundary-layer methods for which the economy and efficiency are also important. In the particular case of the roughness associated with ice accretion on airfoils, the roughness elements cannot be defined and the magnitude of the effects do not justify attempts to follow the more expensive approach.

In this paper we adopt the Cebeci-Smith eddy-viscosity formulation for flow over rough surfaces and extend it to compute turbulent flows over iced airfoils with a finite-difference method based on the solution of the boundarylayer equations with the interactive procedure described in Ref.7. Section 2 discusses the method currently developed and also describes a new method for performing the inverse boundary-layer calculations which is under investigation. Section 3 presents results for the NACA 0012 airfoil with ice shapes computed with the fortified LEWICE $\operatorname{code}^{8}$ and the total drag coefficients computed by the interactive boundary-layer (IBL) method developed by Cebeci $^{7}$ and described in Refs. 8 and 9. The paper ends with a summary of the more important conclusions.

\subsection{Turbulence Model for Iced Airfoils}

We use the calculation method of Ref. 7, which is based on the solution of the twodimensional incompressible boundary-layer equations, which employ the eddy-viscosity concept to model the Reynolds shear-stress term

$$
\begin{gathered}
\frac{\partial u}{\partial x}+\frac{\partial v}{\partial y}=0 \\
u \frac{\partial u}{\partial x}+v \frac{\partial u}{\partial y}=u_{e} \frac{d u_{e}}{d x}+v \frac{\partial}{\partial y}\left(b \frac{\partial u}{\partial y}\right)
\end{gathered}
$$

where $b=1+\varepsilon_{m} / v$. On the airfoil, Eqs. (1) and (2) are subject to the boundary conditions

$$
\begin{gathered}
y=0, u=v=0 \\
y=\delta, \quad u=u_{e}(x)=u_{e}^{o}(x)+\delta u_{e}(x)
\end{gathered}
$$

where $u_{e}^{o}(x)$ denotes the inviscid velocity and $\delta u_{e}(x)$ the perturbation velocity due to viscous effects which is given by

$$
\delta u_{e}(x)=\frac{1}{\pi} \int_{x_{a}}^{x_{b}} \frac{d}{d \sigma}\left(u_{e} \delta^{*}\right) \frac{d \sigma}{x-\sigma}
$$

in the interaction region $\left(x_{a}, x_{b}\right)$. For the calculation of wake flow, Eqs. (1) and (2) are subject to conditions on the dividing centerline $y_{c}$

$$
y=y_{c}, v=0
$$

and to freestream conditions

$$
y \rightarrow \pm \infty, u \rightarrow u_{e}(x)=u_{e}^{o}(x)+\delta u_{e}(x)
$$

As discussed in Ref. 10, Eqs. (3b) and (4) 
can be written as

$$
u_{e}(x)=u_{e}^{o}(x)+\sum_{j=1}^{n} c_{i j}\left(u_{e} \delta^{*}\right)_{j}
$$

Here $c_{i j}$ denotes the interaction coefficient matrix, which is obtained from a discrete approximation to the Hilbert integral in Eq. (4). In this form, Eq. (6) provides an outer boundary condition for the viscous-flow calculation, which represents the viscousinviscid interaction. It can be generalized to the form

$$
u_{e}(x)=u_{e}^{\kappa}(x)+\sum_{j=1}^{n} c_{i j}\left[\left(u_{e} \delta^{*}\right)_{j}-\left(u_{e} \delta^{*}\right)_{j}^{\kappa}\right]
$$

where $u_{e}^{\kappa}(x)$ corresponds to the inviscid velocity distribution which contains the displacement thickness effect $\left(\delta^{*}\right)^{x}$ computed from a previous sweep, as discussed in Ref. 10.

The numerical solution of the above equations for a given eddy-viscosity formulation was obtained by using Keller's box scheme after the continuity and momentum equations and their boundary conditions are expressed in the following form

$\left(b f^{\prime \prime}\right)^{\prime}+\frac{1}{2} f f^{\prime \prime}+\xi w \frac{d w}{d \xi}=\xi\left(f^{\prime} \frac{\partial f^{\prime}}{\partial \xi}-f^{\prime \prime} \frac{\partial f}{\partial \xi}\right)$

On the airfoil

$$
\begin{aligned}
& \eta=0, \quad f=f^{\prime}=0 \\
& \eta=\eta_{e}, \quad w-\tilde{c}_{i i}\left(\eta_{e} w-f_{e}\right)=g_{i}
\end{aligned}
$$

and in the wake

$$
\begin{aligned}
& \eta=\eta_{-e}, \quad f^{\prime}=w \\
& \eta=0, \quad f=0 \\
& \eta=\eta_{e}, \quad f^{\prime}=w \\
& w-\tilde{c}_{i i}\left[w\left(\eta_{e}-\eta_{-e}\right)-\left(f_{e}-f_{-e}\right)\right]=g_{i}
\end{aligned}
$$


and Smith is given by

$$
\varepsilon_{m}=\left\{\begin{array}{l}
\left(\varepsilon_{m}\right)_{i}=L^{2}\left|\frac{\partial u}{\partial y}\right| \gamma_{t r} \\
\left(\varepsilon_{m}\right)_{o}=0.0168 u_{e} \delta^{*} \gamma_{t r}
\end{array}\right.
$$

where $L$ denotes a modified mixing length

$$
L=0.4 y[1-\exp (-y / A)]
$$

and $A$ is a damping-length parameter

$$
A=26 v_{\tau}^{-1}, \quad u_{\tau}=(\tau / \rho)_{\max }^{1 / 2}
$$

The parameter $\gamma_{t r}$ represents the transition region

$$
\gamma_{t r}=1-\exp \left[-G\left(x-x_{t r}\right) \int_{x_{t r}}^{x} \frac{d x}{u_{e}}\right]
$$

where $x_{t r}$ is the location of the beginning of transition and $G$ is defined by

$$
G=\left(\frac{3}{C^{2}}\right) \frac{u_{e}^{3}}{v^{2}} R_{x_{t r}}^{-1 / 34}
$$

with $R_{x_{t r}}=\left(u_{e} x / v\right)_{t r}$ and $C$ is a constant equal to 60 .

The Cebeci-Smith eddy-viscosity formulation has been extended for flow over a rough surface (Ref. 6) by expressing the modified mixing length $L$ as

$$
L=0.4(y+\Delta y)\{1-\exp [-(y+\Delta y) / A)]\}
$$

recognizing that the velocity profiles for smooth and rough walls can be similar, provided that the coordinates are displaced. In Eq. (19), $\Delta y$ is expressed as a function of an equivalent sand-grain roughness parameter $k_{s}^{+}\left(\equiv k_{s} u_{\tau} / v\right)$, i.e.,

$$
\Delta y=\left\{\begin{array}{cc}
0.9\left(v / u_{\tau}\right)\left[\sqrt{k_{s}^{+}}-k_{s}^{+} \exp \left(-k_{s}^{+} / 6\right)\right] \\
& 5 \leq k_{s}^{+} \leq 70 \\
& (20) \\
0.7\left(v / u_{\tau}\right)\left(k_{s}^{+}\right)^{0.58} & 70 \leq k_{s}^{+} \leq 2000
\end{array}\right.
$$

where $u_{\tau}$ represents the friction velocity given by $u_{\tau}=\sqrt{\tau_{w} / \rho}$.

The Cebeci-Smith eddy-viscosity formulation with $L$ expressed as Eq. (19) has been applied for flows over iced airfoils by providing a link between $k_{s}^{+}$and the roughness of the airfoil surface with ice. This method described below was used for the calculations reported in this paper.

The integral boundary-layer method used to determine the heat transfer coefficient in the LEWICE code (Ref. 12) accounts for the surface roughness of an iced airfoil by expressing the equivalent sand-grain roughness $k_{s}$ as a function of liquid water content (LWC), static air temperature $\left(T_{S}\right)$, and airspeed $\left(V_{\infty}\right)$. With $c$ denoting the airfoil chord and for $\left(k_{s} / c\right)_{\text {base }}=0.00117$, the equivalent sand-grain roughness $k_{s}$ is expressed in the following form

$$
\begin{aligned}
k_{s}= & {\left[\frac{k_{s} / c}{\left(k_{s} / c\right)_{\text {base }}}\right]_{L W C} \cdot\left[\frac{k_{s} / c}{\left(k_{s} / c\right)_{\text {base }}}\right]_{T_{s}} } \\
& \cdot\left[\frac{k_{s} / c}{\left(k_{s} / c\right)_{\text {base }}}\right]_{V_{-} \cdot\left(\frac{k_{s}}{c}\right)_{\text {base }} \cdot c}
\end{aligned}
$$

where each sand-grain roughness parameter is given by

$$
\begin{aligned}
& {\left[\frac{k_{s} / c}{\left(k_{s} / c\right)_{\text {base }}}\right]_{L W C} }=0.5714+0.2457 \\
&+1.2571(L W C)^{2} \\
& {\left[\frac{k_{s} / c}{\left(k_{s} / c\right)_{\text {base }}}\right]_{T_{s}}=0.047 T_{s}-11.27 }
\end{aligned}
$$




$$
\left[\frac{k_{s} / c}{\left(k_{s} / c\right)_{\text {base }}}\right]_{V_{\infty}}=0.4286+0.0044139 V_{\infty}
$$

These expressions, good for both rime and glaze ice, are empirical, are based on experimental data reported in Ref. 12, and do not account for the effect of time on the ice roughness. The experimental data of Olsen et al. ${ }^{13}$ shows that, for glaze ice condition, the roughness increases with time, rapidly at first then more slowly. Their data also shows that rime ice is never as rough as glaze ice.

Recent studies conducted by Shin et al. ${ }^{9}$ show that $k_{s}$ is independent of airspeed $V_{\infty}$ but is also a function of the median volume droplet (MVD) size as well as a function of the parameters in Eq. (21). As a result, they write the expression for sand-grain roughness given by Eq. (13) as

$$
\begin{aligned}
k_{s}= & 0.6839\left[\frac{k_{s} / c}{\left(k_{s} / c\right)_{\text {base }}}\right]_{L W C} \cdot\left[\frac{k_{s} / c}{\left(k_{s} / c\right)_{\text {base }}}\right]_{T} \\
& \cdot\left[\frac{k_{s} / c}{\left(k_{s} / c\right)_{\text {base }}}\right]_{M V D} \cdot\left(\frac{k_{s}}{c}\right)_{\text {base }} \cdot c
\end{aligned}
$$

with

$$
\left[\frac{k_{s} / c}{\left(k_{s} / c\right)_{\text {base }}}\right]_{M V D}=\left\{\begin{array}{r}
1 \\
M V D \leq 20 \\
1.667-0.0333 M V D \\
M V D>20
\end{array}\right.
$$

The present method of applying the CebeciSmith eddy-viscosity formulation for an iced airfoil is to use Eq. (16) with $L$ and $\Delta y$ given by Eqs. (19) and (20) and with $k_{s}$ given by a modified form of Eq. (23). With the eddyviscosity formula defined in this way, Eq. (8) can be solved subject to its boundary conditions given by Eqs. (9) and (10) in an inverse mode.

Up to this point, the current turbulence model for an iced airfoil has been discussed. A new method which not only can make the boundary-layer calculations more efficient but can also lead to substantial savings when used in the Navier-Stokes calculations is being considered and the approach is described briefly here. This new method also uses the Cebeci-Smith eddy-viscosity formulation but replaces the true boundary conditions at $y=0$ by new "wall" boundary conditions defined at some distance $y_{o}$ outside the viscous sublayer to avoid integrating the equations through the region of large y gradients near the surface.

We choose this $y_{0}$ to be the distance given by

$$
y_{0}=\left(v / u_{\tau}\right) y_{0}^{+}
$$

with $y_{0}^{+}$being taken as a specified constant. In that case, the "wall" boundary conditions for $u$ at $y=y_{0}$ can be represented by the law-ofthe-wall expression given by Eq. (6.34) in Cebeci and Bradshaw 14

$$
u_{o}=u_{\tau}\left[\frac{1}{\kappa} \ln \left(y_{o}^{+}+\Delta y^{+}\right)+c-\Delta u^{+}\right]
$$

For Prandtl-Schlichting sand-grain roughness (see Cebeci and Bradshaw ${ }^{14}$ ) the shift in the velocity profile, $\Delta u^{+}$, can be represented by

$$
\Delta u^{+}=\left\{\begin{array}{rr}
3.94-6.276 \ln k_{s}^{+}+2.876\left(\ln k_{s}^{+}\right)^{2} \\
-0.290\left(\ln k_{s}^{+}\right)^{3} & 4.4 \leq k_{s}^{+} \leq 70 \\
\frac{1}{\kappa} \ln k_{s}^{+}-3.70 & k_{s}^{+} \geq 70
\end{array}\right.
$$

It can then be shown from the continuity equation that the second "wall" boundary condition is

$$
\begin{array}{r}
\mathrm{v}_{o}=-y_{0} \frac{d u_{\tau}}{d x}\left\{\frac{u_{o}}{u_{\tau}}+\frac{1}{\kappa}\left(\frac{\Delta y}{y_{0}}\right) \ln \left[1+\frac{1}{\left(\Delta y / y_{o}\right)}\right]\right. \\
\left.-k_{s}^{+} \frac{d\left(\Delta u^{+}\right)}{d k_{s}^{+}}\right\}
\end{array}
$$


where

$$
k_{s}^{+} \frac{d\left(\Delta u^{+}\right)}{d k_{s}^{+}}=\left\{\begin{array}{r}
-6.276+5.753 \ln k_{s}^{+} \\
-0.870\left(\ln k_{s}^{+}\right)^{2} \\
\frac{1}{\kappa}
\end{array}\right.
$$

The changes in shear stress between $y=0$ and $y=y_{o}$ can'be computed from

$$
u_{\tau}^{2}=\frac{\tau_{o}}{\rho}-\alpha y_{0}
$$

where

$$
\alpha=0.3 \frac{d u_{o}^{2}}{d x}-u_{e} \frac{d u_{e}}{d x}
$$

In terms of transformed variables defined by Eq. (12), the "wall" boundary conditions at $\eta=\eta_{0}$ can be written as

$$
\begin{gathered}
f_{o}^{\prime}=\frac{u_{\tau}}{u_{\infty}}\left\{\frac{1}{\kappa} \ln \left[\left(\frac{u_{\tau}}{u_{\infty}}\right) \sqrt{R_{x}}\left(\eta_{o}+\Delta \eta_{o}\right)\right]\right. \\
\left.+c-\Delta u^{+}\right\} \\
\xi \frac{\partial f_{o}}{\partial \xi}+\frac{f_{o}}{2}-\frac{1}{2} \eta_{o} f_{o}^{\prime}=\frac{x \eta_{o}}{u_{\infty}} \frac{d u_{\tau}}{d x}\left[\left(\frac{u_{\infty}}{u_{\tau}}\right) f_{o}^{\prime}\right. \\
\left.+\frac{1}{\kappa} \frac{\Delta \eta}{\eta_{o}} \ln \left(1+\frac{1}{\Delta \eta / \eta_{o}}\right)-k_{s}^{+} \frac{d \Delta u^{+}}{d k_{s}^{+}}\right]
\end{gathered}
$$

Similarly, Eq. (30), which provides the relationship between the wall shear and that at $y=y_{o}$ can be written as

$$
\begin{aligned}
u_{\tau}^{2}= & \frac{u_{\infty}^{2}}{\sqrt{R_{x}}}\left\{b_{o} f_{o}^{\prime \prime}+\eta_{o} \frac{x u_{e}}{u_{\infty}^{2}} \frac{d u_{e}}{d x}\right. \\
& \left.-0.3\left[\eta_{o} \xi \frac{\partial}{\partial \xi}\left(f_{o}^{\prime}\right)^{2}-\eta_{o}^{2} f_{o}^{\prime} f_{o}^{\prime \prime}\right]\right\}
\end{aligned}
$$

where

$$
\eta_{o}=\sqrt{R_{x}}\left(\frac{y_{o}}{x}\right), R_{x}=\frac{u_{\infty} x}{v}
$$

We note that when the momentum equation, Eq. (8), is solved subject to the "wall" boundary conditions at $y=y_{o}$, namely, those given by Eqs. (32) and (33), the modified mixing length expression given by Eq. (19) is now

$$
L=0.4(y+\Delta y)
$$

The resulting inner eddy-viscosity formula in Eq. (16a), expressed in transformed variables without the intermittency term, is

$\left(\varepsilon_{m}\right)_{i}^{+}=\frac{\left(\varepsilon_{m}\right)_{i}}{v}=0.16\left(\eta_{o}+\Delta \eta\right)^{2}\left|f_{o}^{\prime}\right| \sqrt{R_{x}}$

The solution of Eq. (8) subject to those boundary conditions given by Eqs. (32) and (33) is somewhat more involved than the solution with "true" wall boundary conditions since the "new" wall boundary conditions are nonlinear and friction velocity is not known. An efficient and accurate solution procedure requires not only the linearization of the boundary conditions with Newton's method as employed in Keller's box scheme, but also the coupling of the solutions to the wall shear given by Eq. (34).

A convenient numerical approach for the solution procedure is to treat the friction velocity as an eigenvalue and obtain the solutions of Eq. (8) subject to Eqs. (32) and (33) for successive values of $u_{\tau}$. More specifically, if we let $u_{\tau}=w$, then the successive values of $w$ can be determined from the following expression

$$
w^{v+1}=w^{v}-\frac{\phi\left(w^{v}\right)}{(\partial \phi / \partial w)^{v}}, \quad v=0,1,2, \ldots
$$

based on Newton's method. In the above equation, $\phi$ represents essentially the error term resulting from Eq. (34), that is 


$$
\phi\left(w^{v}\right)=\left(w^{v}\right)^{2}-[\text { RHS of Eq. }(28)]=0
$$

The term $\partial \phi / \partial w$ is obtained by solving a set of variational equations obtained by differentiating the difference equations of Eqs. (8), (32) and (33) with respect to $w$.

A better and perhaps a more efficient numerical approach for the solution procedure is to treat $w$ as an unknown and noting that

$$
\frac{\partial w}{\partial \eta}=0
$$

solve the boundary-layer equations as a fourthorder system rather than a third-order system. Both numerical approaches are under investigation.

\subsection{Results and Discussion}

The current method of applying the CebeciSmith eddy-viscosity formulation described in the previous section was used to make calculations for the same icing conditions used in the recent test in the Icing Research Tunnel (IRT) of the NASA Lewis Research Center ${ }^{15}$, and comparisons were made in predicting the measured ice shapes on the leading edge of an NACA 0012 airfoil together with their total drag coefficients. Before we present a comparison between measured and calculated results, it is useful to present a brief summary of the experimental data reported in more detail in Ref. 15.

The measurements were made in the NASA Lewis Icing Research Tunnel on a $6 \mathrm{ft}$ span, 21 in. chord NACA 0012 airfoil with a fiberglass skin. The model was mounted vertically in the center of the test section as shown in Fig. 1. During all icing runs, the model was set at an angle of attack of $4^{\circ}$. The icing conditions reported in Ref. 15 can be grouped as (1) low speed with $V_{\infty}=150 \mathrm{mph}$ and a high liquid water content, LWC of $1.0 \mathrm{~g} / \mathrm{m}^{3}$, and (2) high speed, $V_{\infty}=230 \mathrm{mph}$ and low LWC = $0.55 \mathrm{~g} / \mathrm{m}^{3}$. Water droplet size, MVD, was kept constant at $20 \mu \mathrm{m}$ in both groups. The ice accretion time in group one was 6 minutes and in group two was 7 minutes. Total temperatures in both groups were varied from $28^{\circ} \mathrm{F}$ to $-15^{\circ} \mathrm{F}$ to cover glaze, rime and transition regimes.

\subsection{Comparison Between Calculated and Measured Ice Shapes}

Calculations were made with the fortified LEWICE code for the comparisons with the experimental data. The time step used in the calculations for ice accretion was one minute.

Figure 2 shows a comparison between the calculated and measured ice shapes at an air speed of $150 \mathrm{mph}$ for seven total temperatures in which the ice shape changes from white, opaque rime ice to slushy, clear glaze ice when the temperature is increased. At low temperatures at which the ice shapes correspond to rime ice, the comparison between calculated and measured ice shapes are good, consistent with the previous study reported in Ref. 9. Icing limits are predicted well for temperatures below $18^{\circ} \mathrm{F}$. At warmer temperatures the calculated results predict more run back, which results in more ice accretion beyond the measured icing limits. While the calculated results predict the direction of horn growth of the glaze ice, in general the size of the predicted ice shape is larger than the measured size.

Figure 3 shows a similar comparison for the airspeed of $230 \mathrm{mph}$. As in Fig. 2, computed results agree well with measurements at all temperatures, except at $28^{\circ} \mathrm{F}$ where an overprediction of upper horn ice is seen.

\subsection{Comparison Between Calculated and Measured Drag Coefficients}

A comparison between calculated and measured drag coefficients can be made with the interactive boundary-layer method of Refs. 8 and 9 using the turbulence model given in this paper for an ice shape either given by experiment or computed by the fortified LEWICE code. The former choice is usually not practical for two main reasons. Experimental ice shapes contain discontinuities, and the flowfield calculations require smooth or near smooth shapes. The second, perhaps the 
most important reason, is the requirement that the extent of ice on the airfoil be known and this is difficult to measure or specify. For these reasons, the calculations here were made using the ice shapes determined by the fortified LEWICE code, as described in the previous subsection.

A previous study ${ }^{9}$, employing an approach similar to the study conducted for the Olsen et al. data ${ }^{13}$ taken on a NACA 0012 airfoil, showed that while the calculated drag coefficients predicted the correct trend with change in total temperatures ranging from $32^{\circ} \mathrm{F}$ to $-15^{\circ} \mathrm{F}$, the magnitude of the drag coefficients were lower than the measured ones, especially for the rime ice. This difference may be due to (1) the turbulence model and/or (2) the roughness associated with the iced surface.

While the present turbulence model has been evaluated and found to be satisfactory for turbulent flows over rough surfaces, its accuracy still remains to be explored for iced airfoils, since this model primarily uses the correlations developed for high Reynolds number flows over flat plates with roughness. The correlation between the drag of a flat plate covered with uniform sand-grain roughness and the drag of irregular ice shapes on airfoils is not at all well established. The ice attached to the leading edge is in a flowfield in which the inviscid surface velocity varies between the extremes of zero at the stagnation point and the maximum velocity, and ice particles may be subject to what is known as the drag magnification. This concept was advanced by $\mathrm{Nash}^{16}$ and it was confirmed experimentally that the drag of objects placed in a velocity field is not simply proportional to the local dynamic pressure but varies according to a different law, dependent on the initial momentum loss and some power of the local velocity. Thus the drag contribution of roughness placed in a high velocity region may be more than that deduced from the application of flat-plate values locally. Not accounting for the drag magnification in the turbulence model may lead to drag values lower than those observed experimentally.

A numerical study was conducted to investigate ways to compensate for this deficiency in the roughness model (i.e. drag magnification): The current IBL method calculates the drag coefficients with the roughness parameter $\left(k_{s}\right)_{\mathrm{IBL}}$, given by

$$
\left(k_{s}\right)_{\mathrm{IBL}}=2\left(k_{s}\right)_{\mathrm{Eq} .(23)}
$$

applying it only over the surface of the ice. For this numerical study, the code was modified to allow for roughness on both the ice and the airfoil surface downstream of the ice to investigate the effect of the extent of roughness on drag. The results showed that agreement between calculated and measured drag coefficients for rime ice shapes became much better by extending the range of the roughness on the airfoil surface and placing a lower limit of $k_{s} / c=0.002$ on the equivalent sand grain roughness, which otherwise would become very small for rime ice. The extent of the roughness which resulted in the best agreement with the experimental drag coefficients for rime ice shapes was found to be 50 percent of the airfoil chord, and this extent was used in all drag calculations presented in this paper.

Table 1 and Figs. 4 and 5 show a comparison between the calculated and measured drag coefficients for the ice shapes shown in Figs. 2 and 3, respectively. As can be seen, the values of the drag coefficient remain nearly constant up to around $12^{\circ} \mathrm{F}$ for both speeds before they increase sharply with increasing temperature as the ice shape changes to that of glaze ice. The adjustment made by extending the range of roughness on the airfoil allows the calculated drag values to agree well with experimental data at low temperatures. The computed drag coefficients begin to rise sharply at around $18^{\circ} \mathrm{F}$ and reach a peak at $22^{\circ} \mathrm{F}$ for $\mathrm{V}_{\infty}=150 \mathrm{mph}$. Up to this temperature, the trend of calculated results and their magnitudes are in good agreement with measurements. However, for temperatures higher than $22^{\circ} \mathrm{F}$, while the computed drag coefficients begin to decrease, the measured ones continue to rise sharply until $28^{\circ} \mathrm{F}$ before they start decreasing rather sharply. For $V_{\infty}=$ $230 \mathrm{mph}$, however, the calculated results does a good job of following the trend in measured values. A typical computing time (CPU time only) for a calculation with multiple time steps was less than 50 seconds on a CRAY X-MP. 
Figure 6 shows the variation of the drag coefficient of the airfoil with angle of attack for a fixed ice shape computed at $a=4^{\circ}, V_{\infty}=$ $150 \mathrm{mph}, \mathrm{T}_{\mathrm{t}}=22^{\circ} \mathrm{F}$ (Fig. 2c). The calculated drag coefficients for angles of attack from $0^{\circ}$ to $4^{\circ}$ agree very well with experimental data, and the calculations exhibit no numerical difficulties. In the angle of attack range of $4^{\circ}$ to $8^{\circ}$ it was only possible to compute drag coefficients for the values of $\alpha$ indicated in Fig.

6. For intermediate values of $\alpha$, the numerical solutions for wake flow did not converge properly, so the calculations could not be completed. The cause for this behavior of the code is under investigation. Except for the difficulties in convergence at these intermediate values of $\alpha$, the drag coefficients computed without any convergence problems and shown in Fig. 6 indicate a very good agreement with measured values.

\subsection{Concluding Remarks}

The results presented in this paper, as those in a previous paper (Ref. 9) indicate that a combination of LEWICE and IBL provide an efficient and reasonably accurate tool for predicting ice shapes on airfoils and for determining their effect on the increase of drag. Improvements are needed, however, in the interactive boundary-layer method so that the occasional lack of convergence of the solutions at angles of attack near and/or post-stall will be resolved. Studies are also needed to better estimate the extent of roughness on the airfoil surface. Finally, further work is needed to determine why predicted ice profiles are larger than the measured profiles at the warmer temperatures.

\subsection{References}

1. Schlichting, H., "Experimenelle Untersuchungen $\mathrm{Zum}$ Rauhikeitsproblem," Ing. Arch., Vol. 7, pp. 1-34, 1936 (NACA TM 823, 1937).

2. Nikuradse, J., "Stomungsgesetze in rauher Rohren," Forsch. Arb. Ing.-Wes. No. 361, 1933.
3. Hosni, M., Coleman, H. and Taylor, R. "Calculation of Rough-Wall Turbulent Boundary-Layer Heat Transfer," AIAA Paper 91-0161, 1991.

4. Boyle, R.J, and Civinskas, K.C., "TwoDimensional Navier-Stokes Heat Transfer Analysis for Rough Turbine Blades," AIAA Paper 91-2129, 1991.

5. Cebeci, T. and Smith, A.M.O., Analysis of Turbulent Boundary Layers, Academic Press, N.Y., 1974.

6. Cebeci, T. and Chang, K.C., "Calculation of Incompressible Rough-Wall BoundaryLayer Flows," AIAA Journal, Vol. 16, No. 7, pp. 73-735, July 1978.

7. Cebeci, T., "Calculation of Flow Over Iced Airfoils," AIAA Journal, Vol. 27, No. 7, pp. 853-861, 1989.

8. Cebeci, T., Chen, H. H. and Alemdaroglu, N., "Fortified LEWICE with Viscous Effects," Journal of Aircraft, Vol. 28, No. 9, pp. 564-571, Sept. 1991.

9. Shin, J., Berkowitz, B., Chen, H.H. and Cebeci, T., "Prediction of Ice Shapes and Their Effect on Airfoil Performance," AIAA Paper No. 91-0264, Jan. 1991.

10. Cebeci, T., Clark, R.W., Chang, K.C., Halsey, N.D. and Lee, K., "Airfoils with Separation and the Resulting Wakes," Journal of Fluid Mechanics, Vol. 163, pp. 320-347, 1986.

11. Bradshaw, P., Cebeci, T. and Whitelaw, J.H., Engineering Calculation Methods for Turbulent Flows, Academic Press, 1981.

12. Ruff, G.A. and Berkowitz, B.M., "Users Manual for the NASA Lewis Ice Accretion Prediction Code (LEWICE)," NASA CR185129, 1991.

13. Olsen, W., Shaw, R.J. and Newton, J., "Ice Shapes and the Resulting Drag Increase for a NACA 0012 Airfoil," NASA TM-83556, 1984. 
14. Cebeci, T. and Bradshaw, P., Physical and Computational Aspects of Convective Heat Transfer, Springer-Verlag, N.Y., 1988.

15. Shin, J. and Bond, T., "Results of an Icing Test on a NACA 0012 Airfoil in the NASA Lewis Icing Research Tunnel," AIAA Paper No. 92-0647, Jan. 1992.

16. Nash, J.F., "Magnification of Roughness Drag by Pressure Gradient," National Physical Lab. Aero Note 1036, Oct. 1956. 
Table 1.-Effect of total air temperature on drag coefficient. $\left(\alpha=4^{\circ}, M V D=20 \mu \mathrm{m}\right)$

\begin{tabular}{|c|c|c|}
\hline $\begin{array}{c}\text { Total } \\
\text { temperature, } \\
{ }^{\circ} \mathrm{F}\end{array}$ & $\begin{array}{c}\text { Experimental } \\
\text { drag } \\
\text { coefficient }\end{array}$ & $\begin{array}{c}\text { Calculated } \\
\text { drag } \\
\text { coefficient }\end{array}$ \\
\hline 28 & 0.0578 & 0.0346 \\
25 & .0540 & .0372 \\
22 & .0315 & .0392 \\
18 & .0271 & .0351 \\
12 & .0229 & .0217 \\
1 & .0229 & .0209 \\
-15 & .0233 & .0202 \\
\hline
\end{tabular}

(a) $V_{\infty}=150 \mathrm{mph}, \mathrm{LWC}=1.0 \mathrm{~g} / \mathrm{m}^{3}, \mathrm{t}=6 \mathrm{~min}$.

\begin{tabular}{|c|c|c|}
\hline $\begin{array}{c}\text { Total } \\
\text { temperature, } \\
{ }^{\circ} \mathrm{F}\end{array}$ & $\begin{array}{c}\text { Experimental } \\
\text { drag } \\
\text { coefficient }\end{array}$ & $\begin{array}{c}\text { Calculated } \\
\text { drag } \\
\text { coefficient }\end{array}$ \\
\hline 28 & 0.0428 & 0.0470 \\
25 & .0371 & .0294 \\
22 & .0311 & .0202 \\
18 & .0268 & .0195 \\
12 & .0255 & .0195 \\
1 & .0234 & .0195 \\
-15 & .0218 & .0192 \\
\hline
\end{tabular}

(b) $V_{\infty}=230 \mathrm{mph}, \mathrm{LWC}=0.55 \mathrm{~g} / \mathrm{m}^{3}, \mathrm{t}=7 \mathrm{~min}$. 


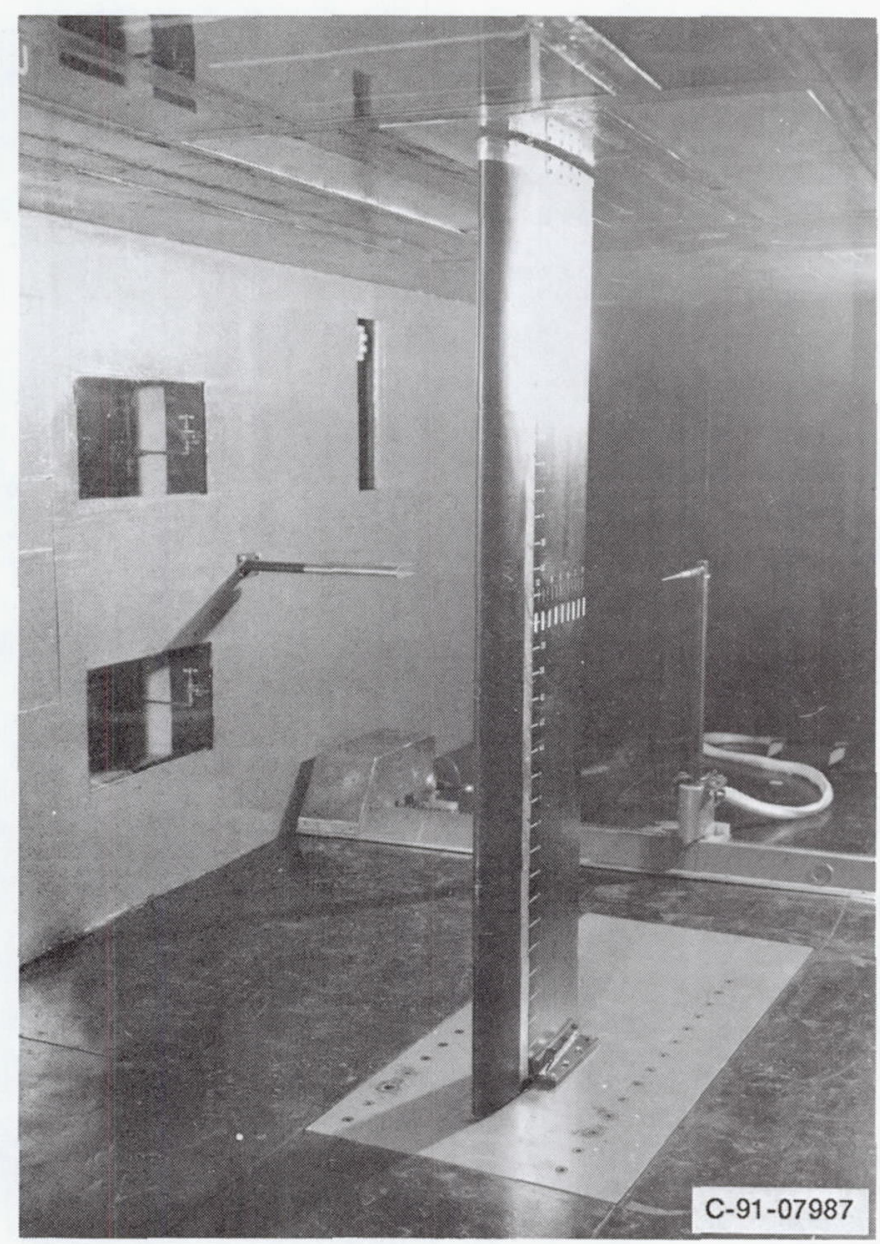

Figure 1.-NACA 0012 airfoil and wake survey probe. 

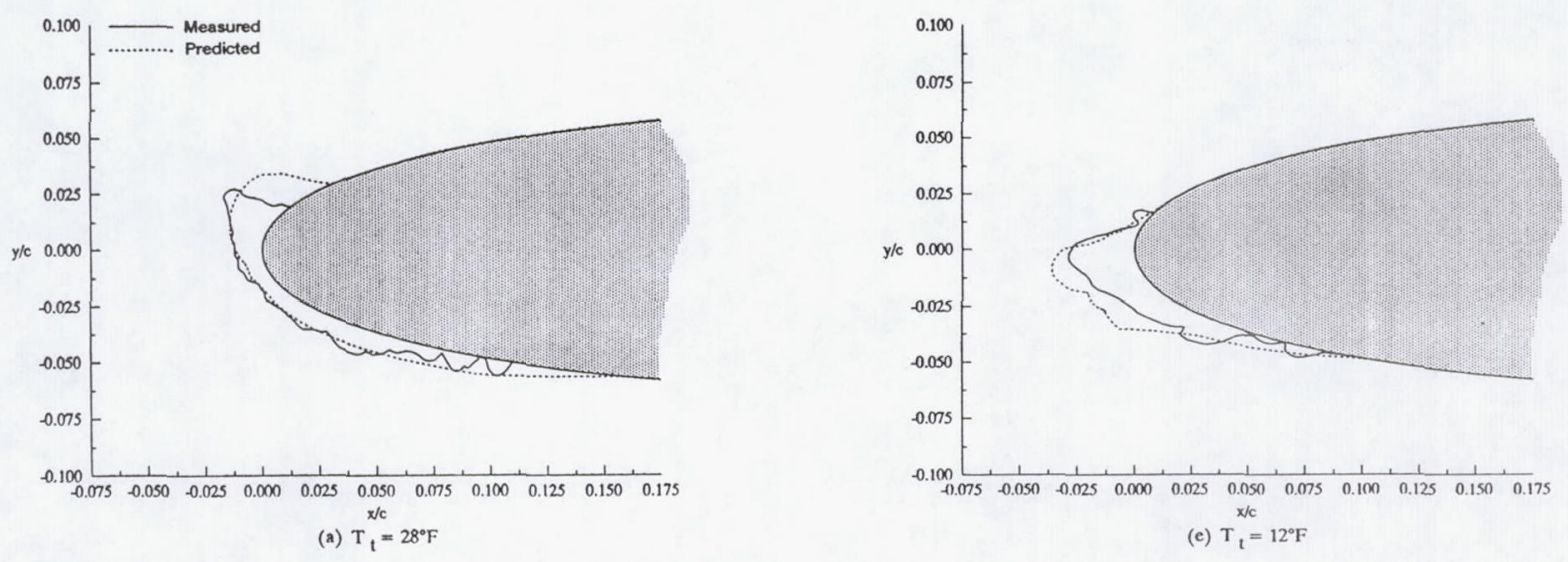

(e) $\mathrm{T}_{\mathrm{t}}^{\mathrm{x} / \mathrm{c}}=12^{\circ} \mathrm{F}$
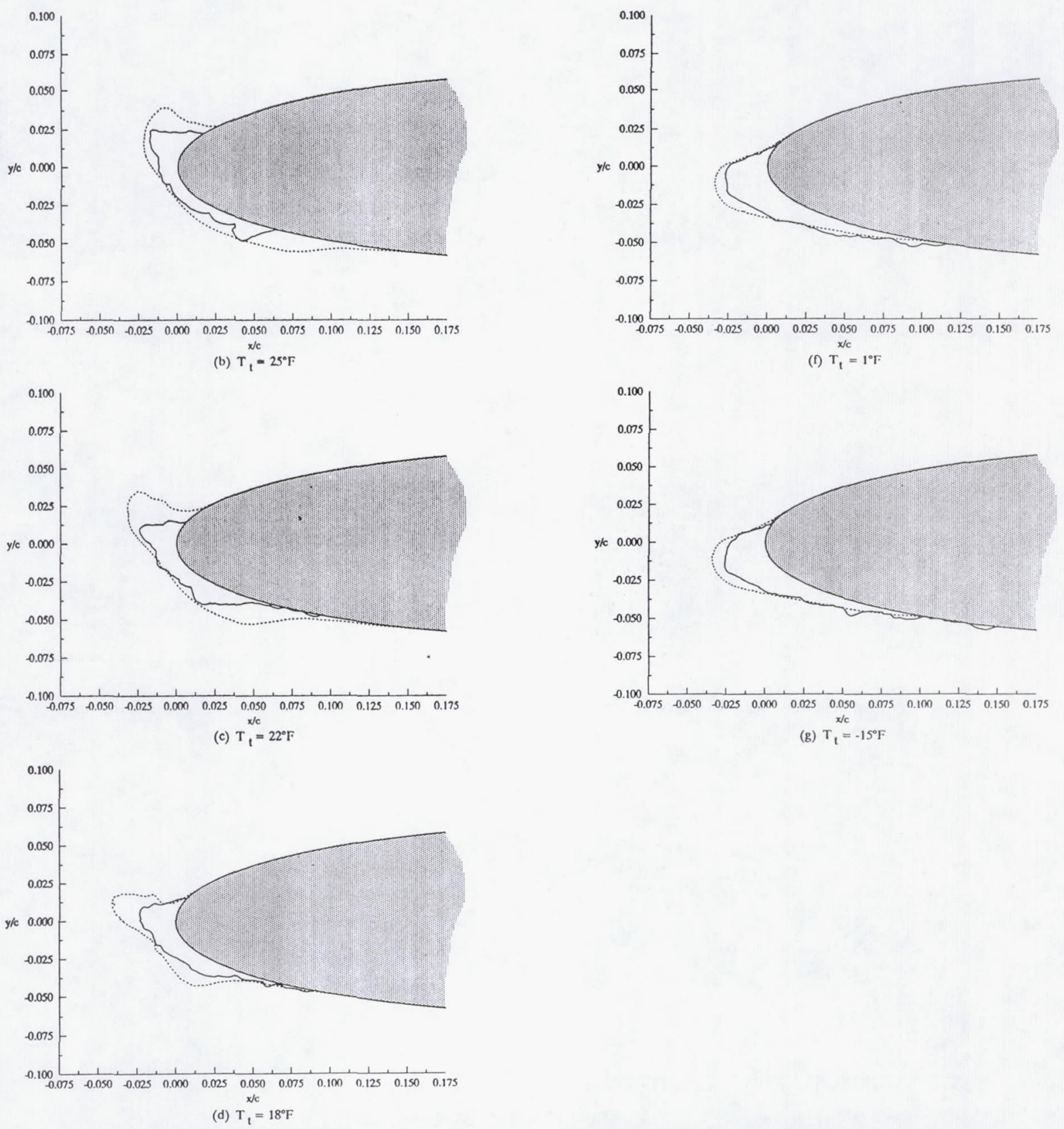

Figure 2.-Effect of total air temperature on ice shape for the experimental conditions in Table 1 (a). 

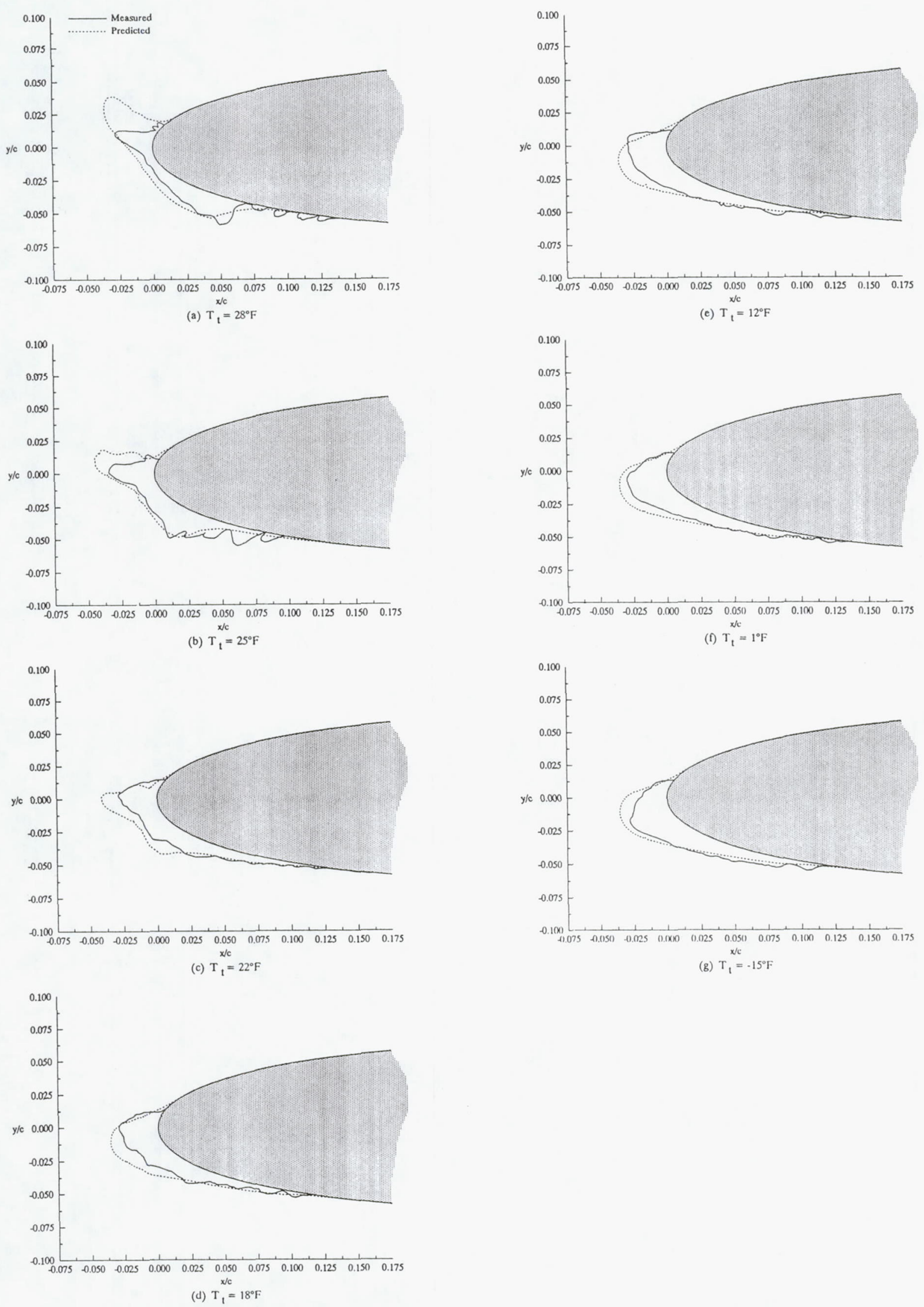

(g) $T_{1}^{x / c}=-15^{\circ} \mathrm{F}$

Figure 3.-Effect of total air temperature on ice shape for the experimental conditions in Table 1 (b). 


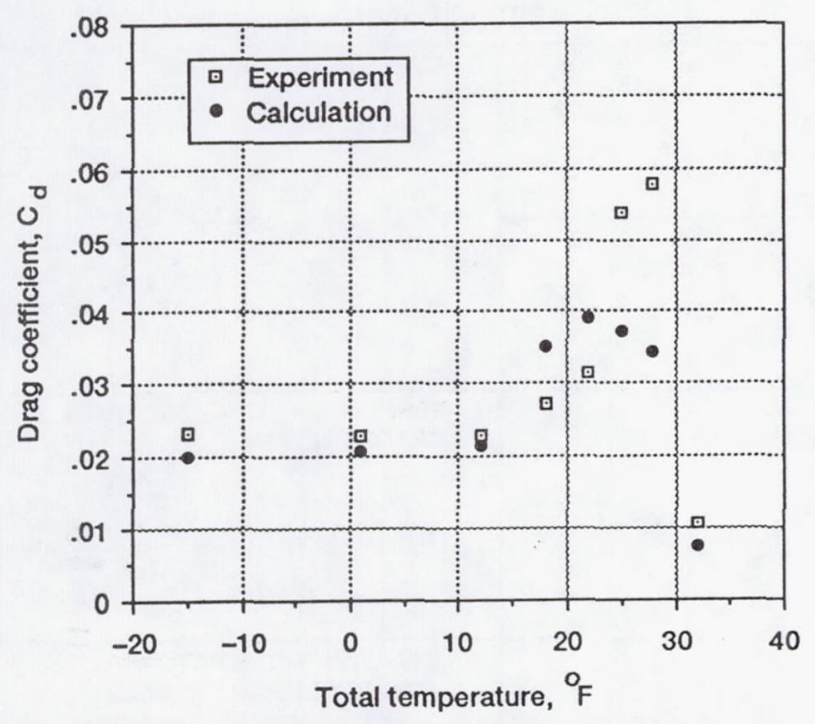

Figure 4.-Effect of total air temperature on the airfoil drag coefficient for the experimental conditions in Table 1(a).

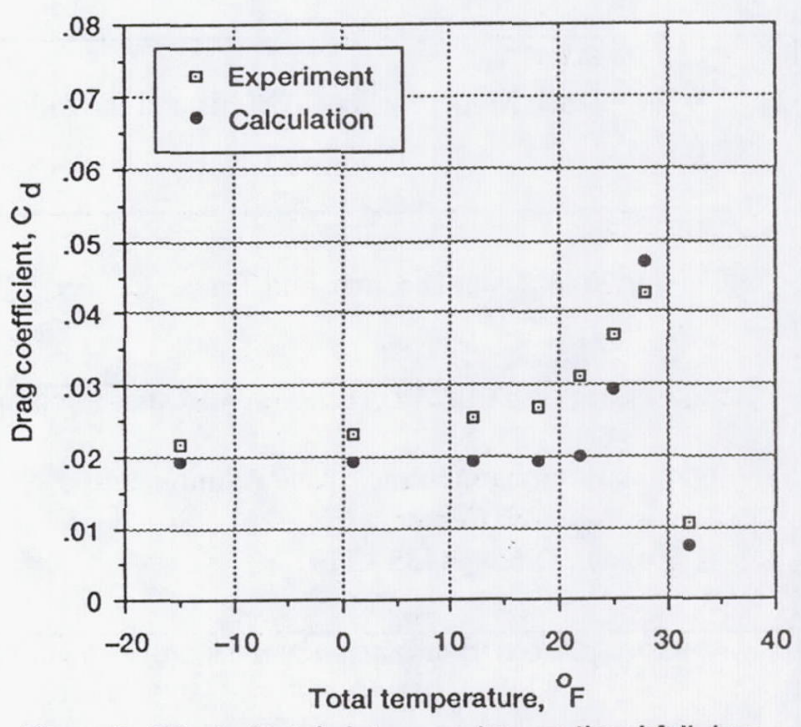

Figure 5.-Effect of total air temperature on the airfoll drag coefficient for the experimental conditions in table 1 (b).

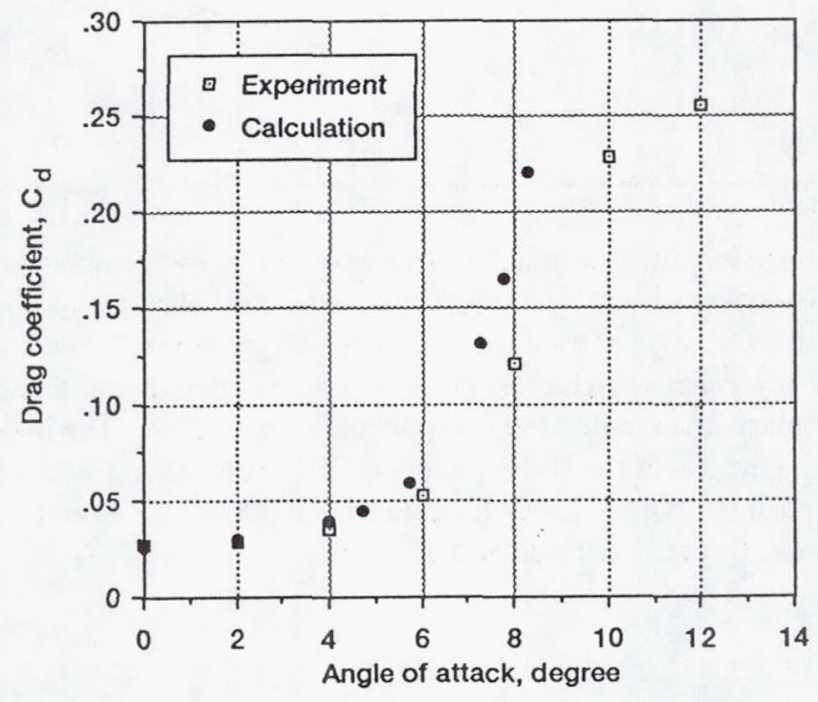

Figure 6.-Variation of the drag coefficient of the airfoil with angle of attack with ice shape corresponding to glaze ice shown in Figure 2 (c). 
Public reporting burden for this collection of information is estimated to average 1 hour per response, including the time for reviewing instructions, searching existing data sources, gathering and maintaining the data needed, and completing and reviewing the collection of information. Send comments regarding this burden estimate or any other aspect of this collection of information, including suggestions for reducing this burden, to Washington Headquarters Services, Directorate for information Operations and Reports, 1215 Jefferson Davis Highway, Suite 1204, Arlington, VA 22202-4302, and to the Office of Management and Budget, Paperwork Reduction Project (0704-0188), Washington, DC 20503.

\begin{tabular}{l|l} 
1. AGENCY USE ONLY (Leave blank) & 2. REPORT DATE
\end{tabular}

4. TITLE AND SUBTITLE

1992 3. REPORT TYPE AND DATES COVERED

A Turbulence Model for Iced Airfoils and Its Validation

Technical Memorandum

Jaiwon Shin, Hsun H. Chen, and Tuncer Cebeci

WU $-505-68-10$

National Aeronautics and Space Administration

Lewis Research Center

Cleveland, Ohio 44135 - 3191

9. SPONSORING/MONITORING AGENCY NAMES(S) AND ADDRESS(ES)

National Aeronautics and Space Administration

Washington, D.C. 20546-0001

8. PERFORMING ORGANIZATION REPORT NUMBER

$E-6760$

10. SPONSORING/MONITORING AGENCY REPORT NUMBER

NASA TM - 105373

AIAA-92-0417

\section{SUPPLEMENTARY NOTES}

Prepared for the 30th Aerospace Sciences Meeting and Exhibit sponsored by the American Institute of Aeronautics and Astronautics, Reno, Nevada, January 6-9, 1992. Jaiwon Shin, NASA Lewis Research Center; Hsun H. Chen and Tuncer Cebeci, California State University, Aerospace Engineering Department, Long Beach, California 90801. Responsible person, Jaiwon Shin, (216) 433-8714.

12a. DISTRIBUTION/AVAILABILITY STATEMENT

Unclassified - Unlimited

Subject Category 02

13. ABSTRACT (Maximum 200 words)

A turbulence model based on the extension of the algebraic eddy-viscosity formulation of Cebeci and Smith developed for two-dimensional flows over smooth and rough surfaces is described for iced airfoils and validated for computed ice shapes obtained for a range of total temperatures varying from $28^{\circ} \mathrm{F}$ to $-15^{\circ} \mathrm{F}$. The validation is made with an interactive boundary-layer method which employs a panel method to compute the inviscid flow and an inverse finite-difference boundary-layer method to compute the viscous flow. The interaction between inviscid and viscous flows is established by the use of the Hilbert integral. The calculated drag coefficients compare well with recent experimental data taken at the NASA Lewis Icing Research Tunnel (IRT) and show that, in general, the drag increase due to ice accretion can be predicted well and efficiently.

14. SUBJECT TERMS

Iced airfoil; Turbulent boundary layer; Interactive boundary layer method; Equivalent sand grain roughness

17. SECURITY CLASSIFICATION OF REPORT

Unclassified
18. SECURITY CLASSIFICATION OF THIS PAGE Unclassified
19. SECURITY CLASSIFICATION OF ABSTRACT Unclassified 


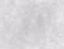

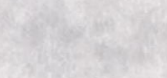

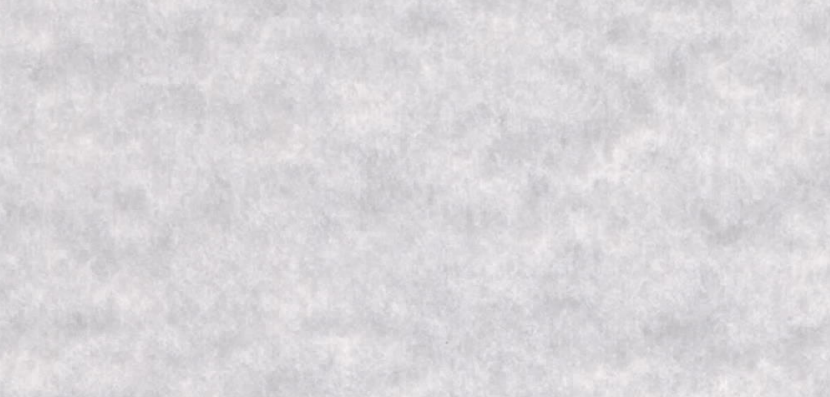

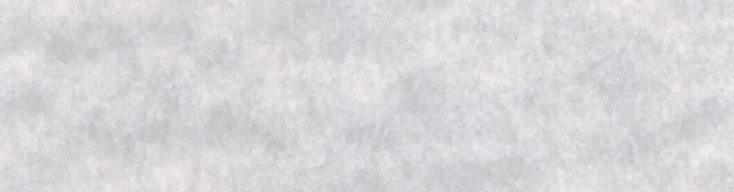


National Aeronautics and Space Administration

Lewis Research Center

Cleveland, Ohio 44135

Official Business

Penalty for Private Use $\$ 300$
FOURTH CLASS MAIL

ADDRESS CORRECTION REQUESTED
|||| $\mid$

Postage and Fees Paid Natıonal Aeronautics an Space Administration NASA 451 